\title{
Chinese and Western Sports Cultural Difference-Based Chinese Sports Development Research
}

\author{
Xiangdong Wang ${ }^{*}$ \\ Institute of Physical Education, Shandong Normal University, Jinan 250014, Shandong, China
}

\begin{abstract}
As globalization speeds up, China has constantly conducted experience exchanges with other western countries in economy, politics, culture, sports and other fields so that strengthened China's comprehensive strength. The paper specific analyzes Chinese and western sports cultures' similarities and differences, and then points out that China is inferior to western countries in football, basketball and other strength type, speed type sports events, while is superior to them in diving and other technical type sports events; establishes grey relational degree model about China's sports events so as to specific research on China sports events advantages and disadvantages, and then puts forward that due to Chinese diet culture and values have great differences from those of western countries, China enjoys exceptional advantages in diving, curling and other sports events, and relational degree values are above 1.1, but by comparing, other events become weakness for China. Research shows that China should learn from other countries strong points to offset its weakness and then strengthen China sports comprehensive strength.
\end{abstract}

Keywords: Grey relational degree method, sports culture, sports differences, sports undertaking.

\section{INTRODUCTION}

Contemporary social competition is not only competition in economy but more is that in comprehensive strength, China sports is also an important part that cannot ignore, therefore by comparing Chinese and western sports cultural differences, it discards the dross and selects the essence and lets China sports to healthy develop [1].

Tang Ling-Ling in the article "Chinese and western sports cultural difference impacts on Chinese school physical education", carried out comparison analysis of Chinese and western culture, got that Chinese and western sports inclined key points were different, which mainly because among Chinese and western different education system [2], Chinese education advocated Confucianism and openness was fewer, China sports were not good in track and field, while for table tennis that was its strong point; western education was open and was easier to get good results in track and field events [3].

Shen Wen-Yan in the article "Discuss on Chinese and western sports cultural difference origins" [4], conducted further investigation and research on Chinese and western diet culture, values, and aesthetic ideology, thought that the west tended to eat meat, beefsteak and other high-calorie foods in diet, which created material foundation for their growing into a big man, and caused westerners like American height to be relative taller, so it was an inborn advantage in basketball aspect.

The paper through investigation and research, it also provided precious opinions for China cultivating international star in future [5].
Chen Rong in the article "Foster Chinese and western sports cultural conflicts and fusion-Chuk-guk and football" [6], began to study from Chinese football origins Chuk-guk, and got that reason for China football being inferior to other western countries was not because of China's insufficient investment in football, by consulting information, it was clear that small countries as Brazil [7], Spain and Argentina kept the position as dominance in world cup, which was because Chinese players understanding on football was not profound, enthusiasm in football was lower and so not well mastered techniques [8].

By consulting information, interviewing scholars, investigating and researching on Chinese and western sports, the paper conducts specific analysis and researches and provides precious suggestions for China future sports development.

\section{CHINESE AND WESTERN SPORTS BASIC IN- FORMATION}

Chinese and western sports cultural differences are not formed in one day, which is related to China's deep-rooted humanistic spirits and value guidance, Tables $\mathbf{1}$ and $\mathbf{2}$ are commonality comparison between Chinese traditional sports culture and western traditional sports culture.

Table 2 is Chinese and western sports culture commonality and difference, now analyze them, the analysis process is as following, and gets conclusions.

\subsection{Conditions of Chinese Sports Participants Amount}

By interviewing nationwide big cities' several key universities, the paper consults recent years' Chinese universities physical education policies, and summarizes Chinese physical education course more popular physical education courses and lists following Table 3. 
Table 1. Chinese and western sports cultural commonality.

\begin{tabular}{|c|c|c|}
\hline Commonality & Chinese Sports Culture & Western Sports Culture \\
\hline \hline Sports cultural background & Can trace back to ancient times & Greece time \\
\hline Sports religious and Gods atmosphere & Buddhism impacts on six classical arts & Origins of Olympics \\
\hline Sports myth atmosphere & Kuafu daily & The creation of the world \\
\hline Sports own post atmosphere & People-centered & People-centered \\
\hline
\end{tabular}

Table 2. Chinese and western sports differences.

\begin{tabular}{|c|c|c|}
\hline Personality & Chinese Sports Culture & Western Sports Culture \\
\hline \hline Pattern of representation & Health maintenance & Athletics \\
\hline Aesthetic taste & Bionic beauty & Benefical beauty \\
\hline Value orientation & Justice outweighing benefit & Body and mind separated \\
\hline Way of thinking & Body and mind unified \\
\hline
\end{tabular}

Table 3. Chinese sports each event participants' amount situation.

\begin{tabular}{|c|c|c|c|c|}
\hline & Ball Type & Water Sports & Small Event & Others \\
\hline \hline Frequency & 91 & 345 & 282 & 84 \\
\hline Percentage & $9 \%$ & $34.5 \%$ & $28.2 \%$ & $8.4 \%$ \\
\hline
\end{tabular}

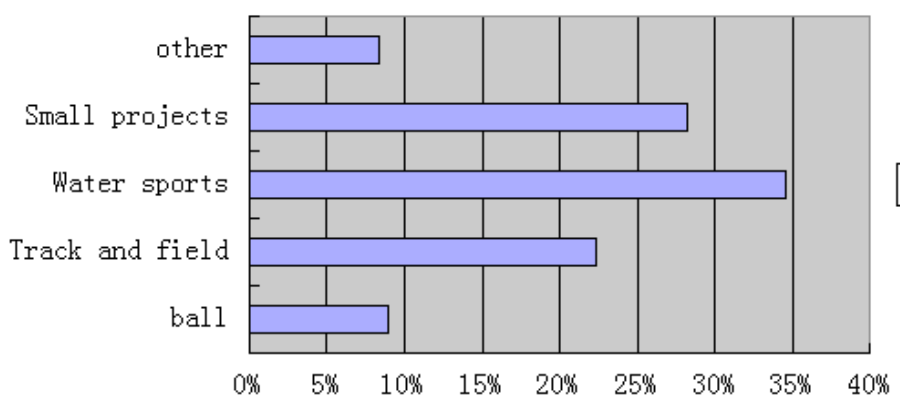

Fig. (1). In sports in our country the number of body.

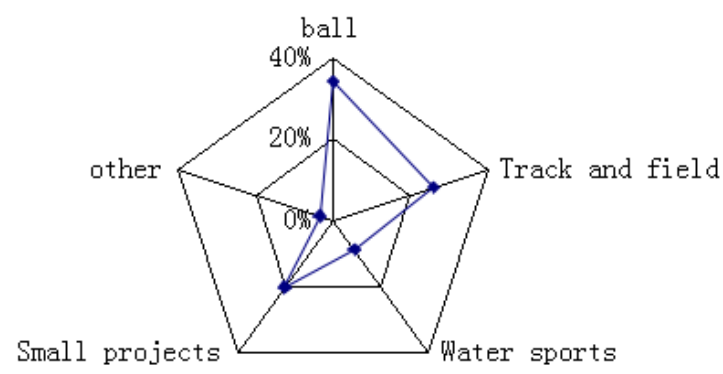

proportion( $(\%)$

Fig. (2). In west sports in country the number of body.

In order to make readers more clear about China's main sports events, it specially draws following figure. Make statistical analysis of Chinese sports events participants amount situation, and bases on analysis, combines with statistical Figs. (1 and 2), it gets conclusions and further points out Chinese public sports participation conditions.
According to above Chinese and foreign sports events statistical analysis as Table $\mathbf{4}$, it gets that Chinese main events are table tennis, swimming and so on; while western countries main sports events are track and field, football, basketball, rugby and other sports events of more advantages in endurance and bodily form. 
Table 4. Western sports events participants' amount situation.

\begin{tabular}{|c|c|c|c|c|}
\hline & Ball Type & Water Sports & Small Event & Others \\
\hline \hline Frequency & 487 & 79 & 194 & 89 \\
\hline Percentage & $33.9 \%$ & $8.9 \%$ & $20.4 \%$ & $3.4 \%$ \\
\hline
\end{tabular}

Table 5. Chinese sports course content.

\begin{tabular}{|c|c|c|c|c|c|c|}
\hline Course content & Ball & Badminton & Sports Dance & Aerobics & Martial Arts & Table Tennis \\
\hline \hline Domestic (\%) & 20.6 & 22.7 & 10.4 & 10.3 & 10.9 & 25.1 \\
\hline
\end{tabular}

Table 6. Foreign countries sports course content.

\begin{tabular}{|c|c|c|c|c|c|}
\hline Course Content & Else & Rugby & Swimming & Basketball & Football \\
\hline \hline Domestic (\%) & 17.4 & 30.5 & 6.3 & 20.7 & 25.1 \\
\hline
\end{tabular}

Table 7. Foreign students and teachers' satisfaction with sports course content.

\begin{tabular}{|c|c|c|c|c|c|}
\hline Evaluation & Very Satisfied & Satisfied & General & Not Satisfied & Very Dissatisfied \\
\hline \hline Domestic students & $38 \%$ & $20 \%$ & $26 \%$ & $9 \%$ & $7 \%$ \\
\hline Foreign students & $21 \%$ & $64 \%$ & $10 \%$ & $2 \%$ & 0 \\
\hline Domestic teachers & $10 \%$ & $30 \%$ & $58 \%$ & $8 \%$ & $2 \%$ \\
\hline Foreign teachers & $15 \%$ & $48 \%$ & $27 \%$ & \\
\hline
\end{tabular}

\subsection{Chinese and Foreign Sports Education Establish- ment Similarities and Differences as Well as Satisfaction}

Below Tables 5-7 are Chinese main universities sports course content establishment statistical table, data is from "China's education comprehensive statistical yearbook", and general administration of sport of China relevant investigation reports. Draw above data into following statistical Figs. (3-5), and further analyze data reflected features:

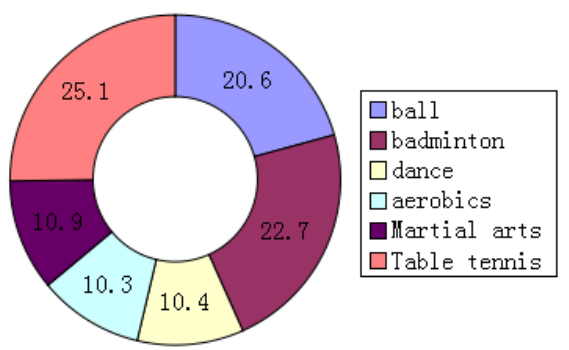

Fig. (3). In our country sports in country the number of body.

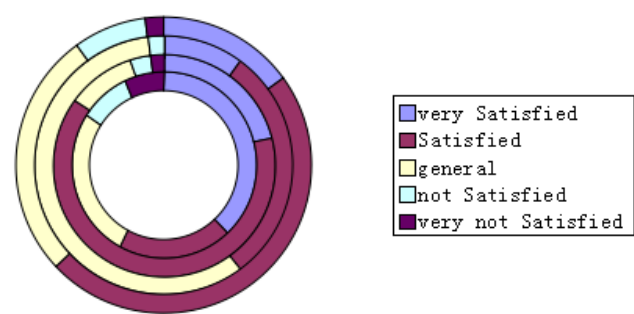

Fig. (5). Foreign students and teachers of physical education contents.

Make statistical analysis of foreign students and teachers' satisfaction with sports course content, analysis statistical figure as following, and get relevant conclusions with the statistical figure.

According to above ring Fig. (5), it gets that no matter domestic or foreign teachers, domestic students or foreign students, all are basically satisfied with native sports course and events, but there are still some parts to be improved,

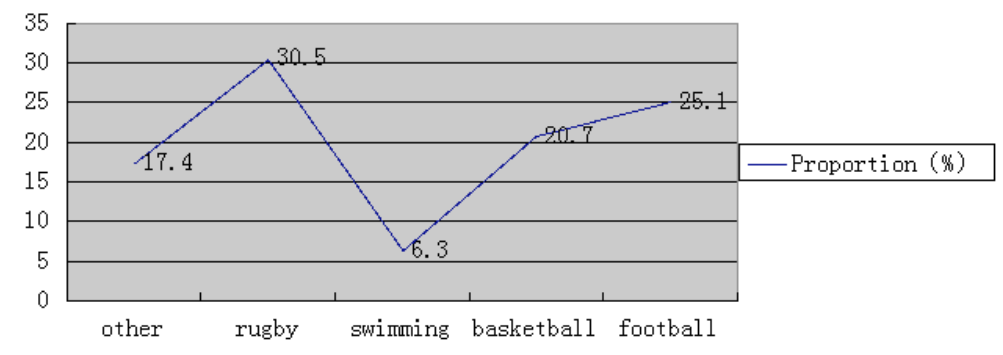

Fig. (4). In west sports in country the number of body. 
Table 8. Domestic and foreign students' sports teaching modes.

\begin{tabular}{|c|c|c|c|c|c|}
\hline & Regular Classes & Professional Course & Consolidated Course & Health Maintenance Course & Optional Course \\
\hline \hline Domestic school & $46.2 \%$ & $23.8 \%$ & $10.1 \%$ & $13.7 \%$ & $6.2 \%$ \\
\hline Foreign school & $30.0 \%$ & $40.0 \%$ & $23.7 \%$ & $3.1 \%$ & $3.2 \%$ \\
\hline
\end{tabular}

Table 9. Domestic sports teacher education background.

\begin{tabular}{|c|c|c|c|c|}
\hline & Graduate Student and Above & Undergraduate Course & Junior College & High School and Below \\
\hline \hline Number of people & 89 & 276 & 462 & 36 \\
\hline Proportion & $7 \%$ & $35 \%$ & $56 \%$ & $2 \%$ \\
\hline
\end{tabular}

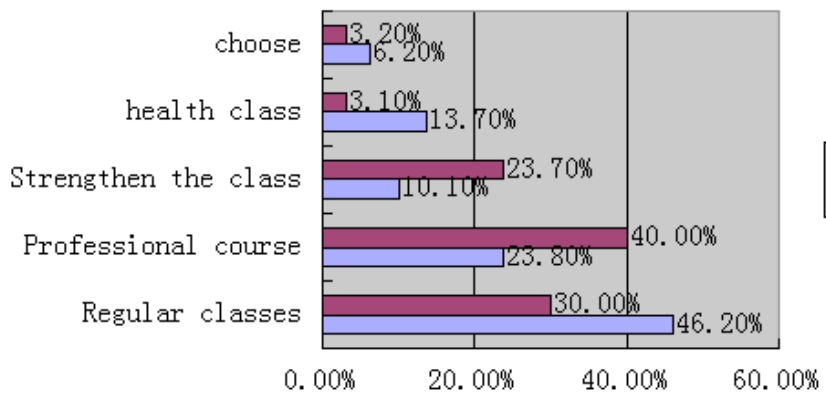

Fig. (6). College students' physical education class teaching form.

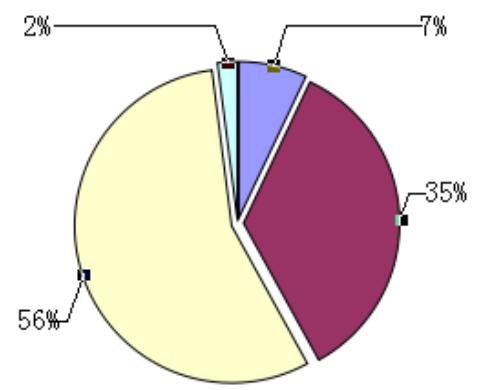

$$
\begin{aligned}
& \square \text { graduate student } \\
& \square \text { Undergraduate course } \\
& \square \text { college } \\
& \square \text { High school and the following }
\end{aligned}
$$

Fig. (7). Domestic sports teachers' qualifications.

domestic and foreign sports course concentration extents are different, which causes domestic and foreign sports talents differences, China should learn from others' strong points to offset its weak points.

\subsection{Domestic and Foreign Students' Sports Education Form}

Tables $\mathbf{8}$ and $\mathbf{9}$ are domestic and foreign sports education modes table, data is from "China's education comprehensive statistical yearbook", general administration of sport of China and China statistical yearbook relevant investigation reports. Utilize mathematical analysis method to draw above data into statistical figure, and then analyze and get conclusions:

In order to make readers to further understand domestic and foreign schools' sports teaching modes, it gets following bar Fig. (6).
By above bar statistical Fig. (7), we can see that domestic mainly cultivates quality talents, so most of schools of China in diagram pay more attention to popularization of regular classes; while many foreign schools pay more attention to professional talents cultivation, and in Fig. (7), it indicates they more focus on professional course.

\subsection{Domestic and Foreign Professional Athletes' Propor- tions}

In order to more intuitional reflect domestic and foreign professional athletes' gender distribution, by investigating and analyzing and data statistics, it summarizes following Fig. (8) and Table 10.

According to above bar Fig. (8), it gets that among Chinese professional athletes, male proportion is around $40 \%$, especially for football, basketball, track and field as well as other events' international athletes are very little, and foreign male proportion is larger, international sports stars 


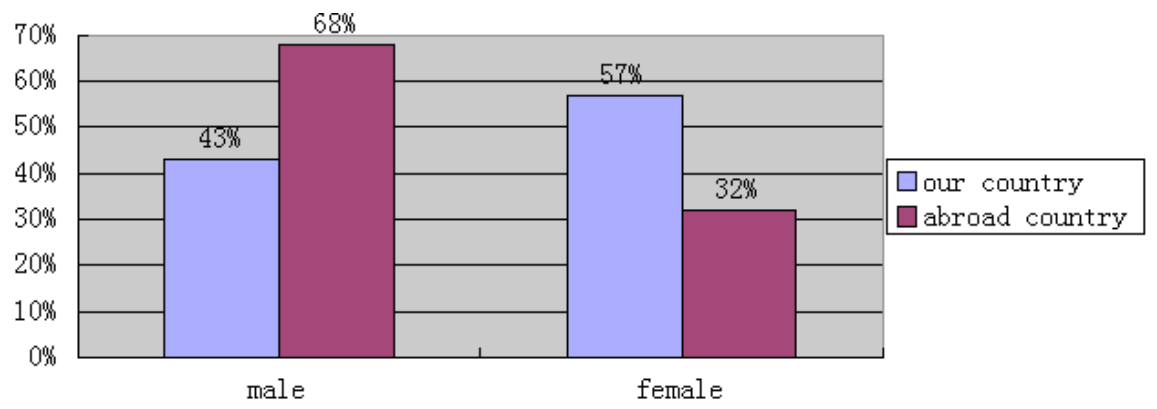

Fig. (8). Domestic professional athletes.

Table 10. Domestic and foreign professional athletes' proportions.

\begin{tabular}{|c|c|c|}
\hline Gender & Male & Female \\
\hline \hline Chinese proportion & $43 \%$ & $57 \%$ \\
\hline Foreign proportion & $68 \%$ & $32 \%$ \\
\hline
\end{tabular}

are more, therefore China should increase cultivation of international sports stars.

\section{GREY RELATIONAL DEGREE METHOD-BASED CHINESE SPORTS RESEARCH}

Chinese sports events are various, but in some events, Chinese sports strength is far behind western countries, these events include football, basketball, track and field and so on, therefore the paper researches on Chinese sports development.

\subsection{Grey Relational Degree Guiding Thoughts}

The significance of grey relational degree analysis is based on system overall development changes, if system changes and factor changes' trends are consistent, then the two correlation degree is larger; if system changes and factors changes' trends are inconsistent, or have certain differences, then the two correlation degree is smaller.

\subsection{Data Handling}

Below Table $\mathbf{1 1}$ is form "Chinese education comprehensive statistical yearbook", general administration of sport of China and relevant documents consulted data, and manual draw following statistical table:

\subsection{Establish Models}

(1) Record Chinese and foreign sports cultural differences influence feature behavior sequence as following:

$$
x_{i}^{\prime}=\left(x_{i}^{\prime}(1), x_{i}^{\prime}(2), x_{i}^{\prime}(3)\right)^{\top}, i=1,2,3 \text {, from which relative }
$$

factor line sequence is:

$$
\begin{aligned}
& x_{1}^{\prime}=(12 \cdot 7,15 \cdot 1,16 \cdot 6,8 \cdot 8,11 \cdot 6,10 \cdot 2,10 \cdot 4,7 \cdot 4,5 \cdot 2,4 \cdot 3,3 \cdot 7) \text {, } \\
& x_{2}{ }^{\prime}=(17,15,17,15,15,14,13,12,12,10,13) \text {; } \\
& x_{3}{ }^{\prime}=(1 \cdot 8,1 \cdot 5,1 \cdot 5,1 \cdot 5,1 \cdot 5,3,1,1 \cdot 5,1 \cdot 5,2,1.5)
\end{aligned}
$$

Therefore it can get:

$$
x_{i}^{\prime}=\left(\begin{array}{ccccccccccc}
12.7 & 15.1 & 16.6 & 8.8 & 11.6 & 10.2 & 5.4 & 5.2 & 5.2 & 3.1 & 1.7 \\
12 & 15 & 17 & 11 & 15 & 14 & 12 & 12 & 12 & 10 & 13 \\
1.7 & 1.5 & 1.5 & 1.7 & 1.3 & 2 & 2 & 1.5 & 1.5 & 2 & 1.5
\end{array}\right)
$$

Define reference sequence

Take Chinese coaches to Chinese sports events satisfaction sequence $x_{0}$ as reference sequence, that:

$$
x_{0}{ }^{\prime}=(11.9,12 \cdot 6,13 \cdot 2,10 \cdot 1,11 \cdot 9,11 \cdot 3,11 \cdot 2,5 \cdot 2,2 \cdot 7,2 \cdot 9,7.0)
$$

\begin{tabular}{|c|c|c|c|c|c|c|c|c|c|}
\hline Course Content & $\begin{array}{l}\text { Water } \\
\text { Event }\end{array}$ & Curling & Badminton & $\begin{array}{c}\text { Martial } \\
\text { Arts }\end{array}$ & $\begin{array}{c}\text { Free } \\
\text { Combat }\end{array}$ & Tennis & Football & Basketball & Else \\
\hline Percentage $\%$ & 15.1 & 8.8 & 11.6 & 10.2 & 10.4 & 5.4 & 5.2 & 4.3 & 3.6 \\
\hline Attention & 15 & 11 & 15 & 14 & 12 & 12 & 12 & 10 & 13 \\
\hline Understanding & 1.5 & 1.5 & 1.5 & 3 & 1 & 1.5 & 1.5 & 2 & 1.5 \\
\hline Satisfaction $\%$ & 12.6 & 9.1 & 11.9 & 11.3 & 11.2 & 7.2 & 3.7 & 3.9 & 7.0 \\
\hline
\end{tabular}

Initialization method data processing

Utilize formula $x_{i}(k)=\frac{x_{i}^{\prime}(k)}{x_{i}^{\prime}(1)}$, to handle with relative factors line sequence, result is as following:

$$
x_{1}(k)=\frac{x_{1}^{\prime}(k)}{x_{1}^{\prime}(1)}=(1,1.02,1.14,0.69,0.99,0.80,0.81,0.58,0.41,0.24,0.13) \text {; }
$$

Table 11. Data statistical table. 


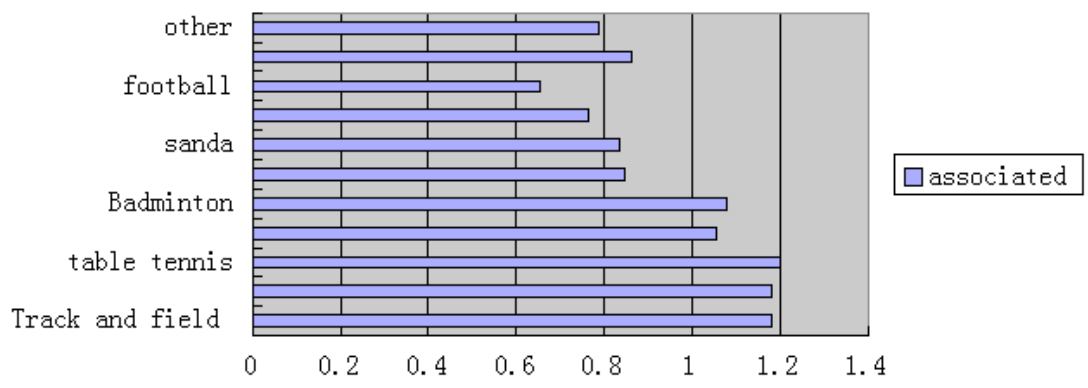

Fig. (9). Correlation value.

$$
\begin{gathered}
x_{2}(k)=\frac{x_{2}{ }^{\prime}(k)}{x_{2}{ }^{\prime}(1)}=(1,0.88,1,0.88,0.88,0.82,0.76,0.71,0.71,0.59,0.76) \\
x_{3}(k)=\frac{x_{3}{ }^{\prime}(k)}{x_{3}{ }^{\prime}(1)}=(1,1,1,1,1,1.33,1.33,1,1,1.33,1)
\end{gathered}
$$$$
\text { Calculate } \min _{1 \leq i \leq 3} \min _{1 \leq k \leq 3} \mid x_{0}{ }^{\prime}-x_{i}(k), \text {, } \max _{1 \leq i \leq 3} \max _{1 \leq k \leq 3}\left|x_{0}{ }^{\prime}-x_{i}(k)\right|
$$

Input $x_{1}(k)=(1,1.02,1.14,0.69,0.99,0.80,0.81,0.58,0.41,0.24,0.13)$;

$$
\begin{gathered}
x_{2}(k)=(1,0.88,1,0.88,0.88,0.82,0.76,0.71,0.71,0.59,0.76) ; \\
x_{3}(k)=(1,1,1,1,1,1.33,1.33,1,1,1.33,1) ; \\
x_{0}{ }^{\prime}=(11.9,12 \cdot 6,13 \cdot 2,10.1,11.9,11 \cdot 3,11.2,5 \cdot 2,2 \cdot 7,2.9,7.0)
\end{gathered}
$$

into above formula and get: $\min _{1 \leq i \leq 3} \min _{1 \leq k \leq 3}\left|x_{0}{ }^{\prime}-x_{i}(k)\right|=28.46$, $\max _{1 \leq i \leq 3} \max _{1 \leq k \leq 3}\left|x_{0}{ }^{\prime}-x_{i}(k)\right|=29.55$

Calculate correlation coefficient

Correlation coefficient computational formula is as following:

$$
\zeta_{i}(k)=\frac{\min _{1 \leq i \leq n} \min _{1 \leq k \leq m}\left|x_{0}^{\prime}(k)-x_{i}(k)+\rho \times \max _{1 \leq i \leq n} \max _{1 \leq k \leq m}\right| x_{0}^{\prime}(k)-x_{i}(k) \mid}{\left|x_{0}^{\prime}(k)-x_{i}(k)+\rho \times \max _{1 \leq i \leq n} \max _{1 \leq k \leq m}\right| x_{0}^{\prime}(k)-x_{i}(k) \mid}
$$

Among them, $\rho$ is resolution ratio, and $\rho \in(0,1)$, $\rho=0.5, \rho$ gets bigger and then relation is bigger.

Input $\left|x_{0}^{\prime}(k)-x_{i}(k)\right|$ each value, and can solve: $\zeta_{1}=(1.24,2.01,0.889,0.778,1.924,0.891,2.02,0.897,0.865,0.898,0.964)$; $\zeta_{2}=(1.24,1.32,0.897,0.977,0.993,0.975,1.201,1.012,1.114,0.989,0.976)$; $\zeta_{3}=(1.24,1.11,1.15,0.967,0.985,0.778,1.96,0.972,1.11,0.874,0.981)$

Calculate correlation degree: Use correlation degree computational formula $r_{i}=\frac{1}{m} \sum_{k=1}^{m} \zeta_{i}(k)$, input:

$\zeta_{1}=(1.14,1.01,0.989,0.978,0.924,0.991,1.02,0.997,0.875,0.898,0.964)$; $\zeta_{2}=(1.14,1.11,0.996,0.987,0.893,0.975,1.201,1.012,1.114,0.989,0.976)$; $\zeta_{3}=(1.24,1.01,1.15,0.877,0.782,0.888,0.897,0.763,2.11,0.774,0.981)$
And get:

$r_{1}=1.089, r_{2}=12.082, r_{3}=1.087, r_{4}=1.064, r_{5}=1.190, r_{6}=$ $0.857, r_{7}=0.844, r_{8}=0.775, r_{9}=0.654, r_{10}=0.8 .62, r_{11}=$ 0.787 .

Evaluation result: Draw above result into statistical Fig. (9), and analyze conclusions:

From above bar statistical Fig. (9), it can get conclusions that among Chinese sports events, relational degrees from high to low are in order table tennis, water events, track and field, badminton, curling, and these events relational degree is above 1.0, it shows Chinese investment in these events, therefore levels are higher, the paper suggests that China should increase investment in basketball, football, tennis, free combat, martial arts some weak strength sports events

\section{CONCLUSION}

At first, the paper researches on Chinese and western sports cultural differences, and points out that due to different countries education ways are different, Chinese and western sports events have their own emphasis, the west dominates football, basketball and other sports events by their tall figure and swift motions and other advantages, though Chinese is not so strong, Chinese athletes catches on some areas in diving, table tennis and other events through knack, fast reaction capacity. Secondly, the paper applies grey relational degree method to further study Chinese sports, and finally gets that among Chinese sports events, the highest relational degree of them is water events, but Chinese football, basketball relational degrees are below 0.8 , which reflects that China publicity and investment strength in football is still not enough, China should employ more professional coaches, and start to foster teenagers of sports talents from teenagers to cultivate more masters sportsmen for China. The paper suggests that it should give Chinese sports superiorities into play and meanwhile take in other countries' ball athletes' cultivation experiences so that make preparation for Chinese sports integrated development.

\section{CONFLICT OF INTEREST}

The author confirms that this article content has no conflict of interest.

\section{ACKNOWLEDGEMENTS}

Declared none. 


\section{REFERENCES}

[1] P. Chen, Z.M. Qin, Y. Yin, and C-D. Xia, "correlation analysis of current situation of regional athletics sports development and society population structure in China," Journal of Beijing Sport University, vol. 30, no. 12, pp. 1610-1613, 2007.

[2] H. Guo, "Summary on chinese sports population research since 1980s," China Sport Science and Technology, vol. 43, no. pp. 3640, 2007.

[3] H. Li, H. Xue, and W. Feng, "Sociological Analysis of Comparison of Chinese Population with the Sports Population of Chinese," Journal of Xi'an Institute of Physical Education, vol. 24, no. 4, pp. 25-28, 2007.

[4] L. Li, J. Yang, T. Yang, and L. Xu, "A research on the sustainable development of evaluation index system of regional sports indus- try," Journal of Beijing Sport University, vol. 10, no. 9, pp. 44-54, 2010.

[5] Z. Miao, and C. Qin, "Sociological analysis of contemporary Chinese sports population structures," Journal of Physical Education, vol. 13, no. 1, pp. 119-121, 2006.

[6] H. Xiao, and L. Fang, "Concept, classification and statistical criteria of sports population," Sports Science Research, vol. 26, no. 1, pp. 7-10, 2005.

[7] J. Xue, and J. Wang, "Analysis on development level of competitive sports of eastern china in the "eleventh five-year" period," Bulletin of Sport Science \& Technology, vol. 19, no. 4, pp. 57-59, 2011.

[8] D. Yan, "Development of sports for all under circumstance of building well-off society," Journal of Wuhan Institute of Physical Education, vol. 40, no. 1, pp. 15-19, 2006.

Received: June 10, 2015

Revised: July 29, 2015

Accepted: August 15, 2015

(C) Xiangdong Wang; Licensee Bentham Open.

This is an open access article licensed under the terms of the (https://creativecommons.org/licenses/by/4.0/legalcode), which permits unrestricted, noncommercial use, distribution and reproduction in any medium, provided the work is properly cited. 